\title{
Short-Term Effects of Fire and Fire-Surrogate Treatments on Avian Nest Survival: A National-Scale Analysis
}

Kerry L. Farris ${ }^{*}, 1$, Sarah J. Converse ${ }^{2}$, Steve Zack ${ }^{1}$, W. Douglas Robinson ${ }^{3}$, Andrew J. Amacher ${ }^{4}$, Thomas Contreras $^{5}$, William L. Gaines ${ }^{6}$, Eran S. Kilpatrick ${ }^{7}$, J. Drew Lanham ${ }^{8}$, Donald Miles ${ }^{9}$, Ghislain Rompré $^{10}$, Kathryn E. Sieving ${ }^{11}$ and Jennifer C. Pierson ${ }^{12}$

${ }^{1}$ Wildife Conservation Society, North America Program, 718 SW Alder Street, Suite 210, Portland, OR 97229, USA

${ }^{2}$ Colorado Cooperative Fish and Wildlife Research Unit, Patuxent Wildlife Research Center, 12100 Beech Forest Road, Laurel, MD 20708, USA

${ }^{3}$ Department of Fisheries and Wildlife, 104 Nash Hall, Oregon State University, Corvallis, OR 97331, USA

${ }^{4}$ Department of Environmental Science, Policy, and Management, 137 Mulford Hall, University of California, Berkeley, CA 94720-3114, USA

${ }^{5}$ Department of Biology, 60 South Lincoln St., Washington \& Jefferson College, Washington, PA 15301, USA

${ }^{6}$ U.S. Forest Service, Okanogan and Wenatchee National Forests, 215 Melody Lane, Wenatchee, WA 98801, USA

${ }^{7}$ Division of Mathematics and Science, University of South Carolina Salkehatchie, PO Box 1337, Walterboro, SC 29488, USA

${ }^{8}$ Department of Forestry and Natural Resources, Clemson University, 261 Lehotsky Hall, Clemson, SC 29634, USA

${ }^{9}$ Department of Biological Sciences, Ohio University, 131 Life Sciences Building, Athens, OH 45701, USA

${ }^{10}$ Department of Biology, 84 W. South Street, Wilkes University, Wilkes-Barre, PA 18766, USA

${ }^{11}$ Department of Wildlife Ecology and Conservation, University of Florida, 110 Newins-Ziegler Hall, Gainesville, FL 32611-0430, USA

${ }^{12}$ Department of Ecosystem and Conservation Science, University of Montana, Missoula, MT 59812, USA

\begin{abstract}
We examined the initial response of avian nest success to mechanical thinning, prescribed fire, and thinning/ prescribed fire combination treatments, designed to reduce fuel loads, at study sites throughout the continental USA as part of the National Fire and Fire Surrogate (FFS) Project. We modeled the daily nest survival of ground-, shrub-, tree-, and snag-nesting bird species to test for effects of: (1) overall treatment (2) specific treatment category (i.e., burn, thin, thin/burn); (3) time since treatment; and (4) study site. Of the 7 species examined, only 2 had top models that included effects of the FFS treatments, the remainder had either constant survival rates, or rates that varied only by study site. The Eastern Towhee had top models that included effects of treatment and study site, while the Red-bellied Woodpecker had top models that included effects of treatment category, time since treatment, and study site. All estimates of treatment, treatment category, and study site were statistically weak with confidence intervals including zero. The lack of clear response patterns observed in this study is likely a consequence of the variability inherent across forest types and taxonomic groups we examined. Forest managers should use our results cautiously and also be encouraged to facilitate opportunities for studies of avian nest survival as a function of fire-surrogate treatments that are regional specific, encompass longer time frames and larger spatial scales.
\end{abstract}

Keywords: Avian nest survival, fire surrogates, forest management, prescribed fire.

\section{INTRODUCTION}

Since Euro-American settlement, many North American forests that traditionally experienced frequent, low-intensity fires have encountered dramatic changes in fire frequency, intensity, and extent due to land management practices

*Address correspondence to this author at the 5708 Bel Aitre Dirve, Klamath Falls, OR 97603, USA; Tel: 001541887 0353;

E-mail: kerrylfarris@gmail.com including fire suppression, selective timber harvest, and livestock grazing $[1,2]$. Compared to pre-Euro-American settlement forests, many of today's forests are characterized by an increased density of small diameter, shade-tolerant trees, a reduction in understory forbs and grasses, and an increase in accumulated duff on the forest floor [3]. Combined, these changes provide fuel for intense and extensive crown fires [2-4] that endanger critical habitat and human lives. 
The pressure to reduce the frequency of catastrophic fires, coupled with the realization that fire plays a fundamental role in the functioning of many North American ecosystems, has led to the implementation of two primary management options: mechanical thinning (removing small diameter understory trees) and prescribed fire. While these two treatments are often employed separately, they are frequently jointly used, with thinning applied first to reduce ladder fuels, followed by prescribed fire treatments [4-7]. While the effectiveness of these treatments, applied either separately or collectively, in the reduction of fuel load and fire risk has been documented [5,7-9], the effects of such treatments on ecological function are relatively unknown (but see [10,11]).

The Fire and Fire Surrogate (FFS) Project was implemented in 2000 to study the effects of fire and fuel reduction treatments on the ecology of forestlands across the United States [12]. Designed by a group of federal, state, and university scientists and managers, the project encompasses 12 study sites spanning the United States in forests with historically frequent, low intensity fire regimes. The goals of this study were to examine the response of soils, fuels, vegetation, insects, and wildlife to 4 distinct treatments: (1) prescribed fire; (2) mechanical thinning; (3) thinning followed by prescribed fire; (4) control - no management intervention. In particular, a central question of the study was whether thinning operates as an ecological "surrogate" for fire, or whether these different treatment types have significantly different ecological effects. Further details of this project can be found at: http://frames.nbii.gov.

Avian nest survival was specified as a key variable within the wildlife component of the study. The passerine bird community is of particular interest to scientists, managers, policy-makers, and the general public due to documented declines of several species in many regions of the Americas. Furthermore, the habitat needs of the passerine bird community encompass the entire range of vertical forest structure (forest floor to forest canopy) - offering the unique opportunity to evaluate the treatment effects of the entire suite of forest structural changes.

While previous studies have separately examined the effects of fire [13-15] and mechanical thinning [16,17] treatments on the avian community, most of this research has relied on the occurrence or abundance of a species to infer positive or negative effects. These studies have provided valuable information on how avian populations respond to such treatments, but the results may be deceptive if measures of occurrence or abundance are not reliable indicators of habitat quality $[18,19]$. Quantifying nest survival in relation to fuel reduction treatments and associated habitat features will offer additional data on the suitability of post-treatment habitats for the avian community, and will also provide information on a primary demographic parameter, reproduction, which governs population-level responses.

The principal objective of this research was to examine the effects of mechanical thinning, prescribed fire, and thinning/prescribed fire treatments on avian nest survival across the national network of FFS Project study sites. Variability in habitat types, timing of treatments and methods are to be expected in such a large project encompassing such spatially disjunct study areas. Our emphasis was not to document such variation but to attempt to find general patterns in the response of the avian nesting community to the implemented treatments. Such information will be a valuable resource to managers concerned with predicting the response of avian communities to fuel reduction activities in fire-dependent forests. Specifically, we wanted to examine how nesting birds responded to overall treatment effects and whether these responses were consistent across study sites; uniform responses across study sites would imply that our findings are generally applicable in forests of this type.

\section{MATERIALS AND METHODOLOGY}

\section{Experimental Design and Study Sites}

The national FFS network consists of 12 study sites distributed across the USA on lands managed by federal and state governments and universities in 10 separate states. This study examined data from a subset of 9 study sites spanning 8 states. The remaining 3 study sites did not contain adequate data for evaluation of our research questions.

The core experimental design consisted of treatments, unit size, replication, and response variables common to all the 9 study sites examined here [12]. Treatment categories included untreated control, prescribed fire, mechanical thinning, and a combination of mechanical thinning followed by prescribed fire. At all but 1 study site, mechanical thinning consisted of the removal of small diameter, understory trees. In the case of the Florida Coastal Plain, mechanical thinning treatments were comprised of mowing and chopping of the saw palmetto understory. All treatments were replicated 3 times at each study site, creating a minimum of 12 experimental units, with the exception of the Blue Mountain study site, where treatments were replicated 4 times for a total of 16 experimental units. Small diameter logging residue (slash) left behind after thinning treatments was scattered across the treated units at all sites except Southwest Plateau, where it was piled. Experimental units were at least 10 ha in size, surrounded by a $50 \mathrm{~m}$ buffer of like treatment. A permanent $50 \mathrm{~m}$ grid system was used to georeference all data observations. Table 1 outlines basic information for each study site including region, location, administrating organization, forest type, and dates of treatments. For more detailed study site descriptions and design information see [12].

\section{Field Methods}

We collected data on nesting birds during the posttreatment breeding seasons (April through July) of 2000 through 2005. In this analysis, "post-treatment" was defined as at least one vegetative dormant season between treatment and data collection. Because the timing of both treatments and data collection varied by site, our data set contains observations from multiple calendar years and ranges from 1-6 years post-treatment. We estimated daily nest survival using standardized nest searching and monitoring protocols [20] which were consistent across the study site network and between field seasons. Nests were located through the use of either systematic searching, the behavior of adult birds as cues to nest locations (e.g., direct flights with food), or 
Table 1. List of Fire and Fire Surrogate (FFS) Study Sites, their General Location, Primary Administrator, Forest Type, and Treatment Dates, Used in this Study

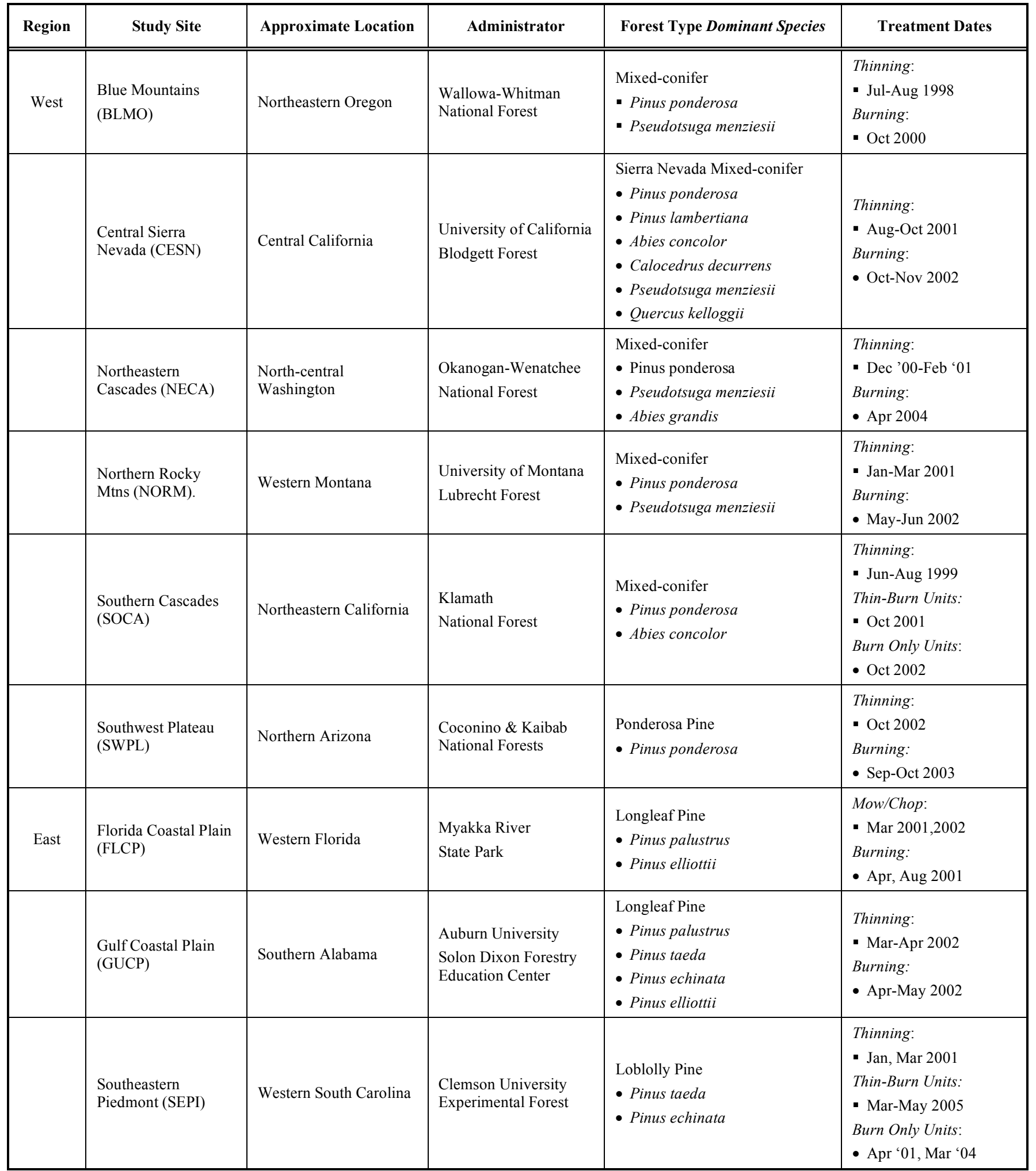

fortuitously flushing incubating and brooding adults. Once located, nests were marked using survey flagging tied to an observation point at least 10-15 m from the nest. Nests were then visited periodically (median observation interval was 3 days) to monitor success or failure. We considered a nest successful during an interval between visits if at least one egg or nestling was alive, or one nestling had fledged, by the following visit [20].

\section{Data Analysis}

We analyzed the nest success data using the logisticexposure method of Shaffer [21]; see also [22]). This method 
is similar to a logistic-type generalized linear model, except that the associated link function includes an exponential term, $1 / t$, where $t$ is the interval length between subsequent nest checks. A primary advantage of this method is that it is not necessary for $t$ to be equal across observation intervals (typically in nesting studies, as in our study, nests are not checked daily, and may be checked at irregular intervals). Using this method, daily survival probabilities, or rates (DSR) are calculated. Daily survival rates are preferable to overall nest survival rates (termed "apparent nest success") because, as observed by Mayfield [23] and many others since, nests that fail early in the nesting cycle are less likely to be located by observers, and so apparent nest success will be biased high. However, to compare with other studies, we also calculated an overall survival estimate $(S)$ calculated as $\operatorname{DSR}^{t}$ where $t$ is the total number of nest exposure days. Input data consisted of a record for each nest check interval, including the species of nest, the length of the interval, the nest fate during the interval, and the type of treatment implemented on the unit where the nest was located (e.g., control, burn, thin, or thin-burn).

We used code authored by T.L. Shaffer in Proc GENMOD of SAS [24] available at http://www.npwrc.usgs. gov/resource/tools/nestsurv/nestsurv.htm. This code facilitates the analysis of nest success data by calculating effective sample sizes for the data sets [22] as well as the $\mathrm{AIC}_{c}$ model selection statistic $[25,26]$ for each model in the model set (described below). In particular, we computed Akaike weights for the various models and model-averaged effect estimates for each of the effects of interest. We used a combination of Akaike weights, $\mathrm{AIC}_{c}$ differences $\left(\triangle \mathrm{AIC}_{c}\right)$, and evidence ratios to focus our discussion of effects. Model weights are considered the primary strength of evidence in favor of a particular model being the actual best model, while both $\triangle \mathrm{AIC}_{c}$ and evidence ratios (ratio of Akaike weights between the top model and the model of interest) can be used to rate the plausibility of a given model relative to the selected best model [27]. Specifically, we report estimates for all effects that appeared in models with Akaike weights $\geq 10 \%$, but focus our discussion of effects on those variables that appeared in models with evidence ratios $<2.0$.

\section{Data and Model Sets}

The overall national FFS nesting data set consisted of observations from 110 species spanning 11 study sites. In examining the national data set, we sought to select representative species from both of the study site regions (west and east) and each of the 4 major nesting guilds (ground, shrub, tree, and snag). In order for a particular species to be considered in this analysis, we established a rule, based on existing patterns of samples in the dataset, that a species had to contribute a minimum of 30 nests and occur at a minimum of 3 study sites for western species, and a minimum of 2 study sites for eastern species. These criteria led to the consideration of 7 different data subsets, or species. The ground-nesting guild included the Dark-eyed Junco (Junco hyemalis) and the Eastern Towhee (Pipilo erythrophthalmus); the shrub-nesting guild included the Dusky Flycatcher (Empidonax oberholseri) and Northern Cardinal (Cardinalis cardinalis); the tree-nesting group had only one representative, the American Robin (Turdus migratorius); and the snag-nesting guild included the Redbreasted Nuthatch (Sitta canadensis) and Red-bellied Woodpecker (Melanerpes carolinus) (Table 2).

We considered a total of 17 candidate models evaluating the effects of the fire and fire-surrogate treatments on the 8 species of nesting birds (Table 3). Within the model set were 4 different models examining treatment effect: (1) no treatment effect (constant survival); (2) a treatment effect common across all treatment types (i.e., thinning is a true "surrogate" for fire with respect to nest success, so effects do not vary by treatment type; TREAT); (3) a treatment effect varying by treatment type, or category (TMTCAT); (4) a treatment effect that changes with time since treatment (TIME). We also considered models which examined the effects of study site (SITE) and both additive and interactive

Table 2. Number of Individual Nests Used in the Analysis of the Effects of Fuel Reduction Treatments on the Daily Nest Survival of 7 Bird Species Representing 4 Nesting Guilds Across 6 Western and 3 Eastern Study Sites as Part of the National Fire and Fire Surrogate Study

\begin{tabular}{|c|c|c|c|c|c|c|c|c|c|}
\hline Dark-eyed Junco & 22 & 25 & 20 & 50 & 16 & 24 & & & \\
\hline Eastern Towhee & & & & & & & 34 & 88 & \\
\hline Dusky Flycatcher & 4 & & 7 & & 27 & & & & \\
\hline Northern Cardinal & & & & & & & 13 & 64 & 15 \\
\hline \multicolumn{10}{|l|}{ Tree } \\
\hline American Robin & 40 & 29 & 11 & 2 & 2 & 14 & & & \\
\hline
\end{tabular}


Table 3. List of Candidate Models Used to Evaluate the Effects of Study Site, Treatment, Treatment Category, and Time Since Treatment on the Daily Nest Survival of 7 Bird Species Observed on 9 Study Sites Between 2000 and 2005 as Part of the National Fire and Fire Surrogate Research Project

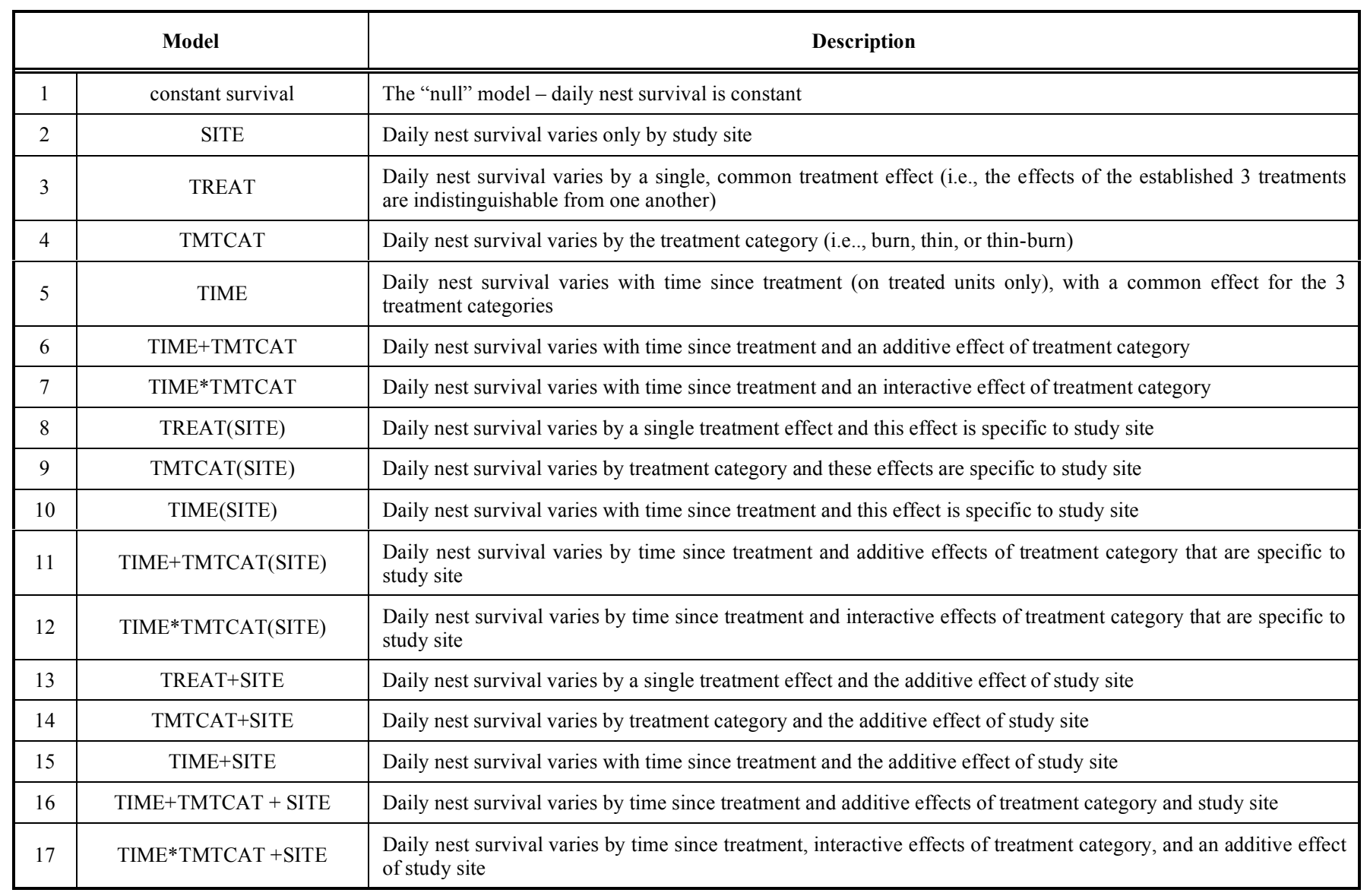

models which included various combinations of the treatment, time and site effects (Table $\mathbf{3}$ ).

\section{RESULTS}

Six-hundred and forty-six (646) individual nests, representing 7 species observed on 9 study sites were included in this analysis (Table 2). In the western region, the most commonly observed species was the Dark-eyed Junco which contributed 157 nests, followed by the American Robin $(\mathrm{n}=98)$, the Red-breasted Nuthatch $(\mathrm{n}=94)$, and the Dusky Flycatcher $(\mathrm{n}=38)$. The most commonly observed species in the eastern region was the Eastern Towhee $(\mathrm{n}=$ 122), followed by the Northern Cardinal $(n=92)$, and the Red-bellied Woodpecker $(\mathrm{n}=45)$.

Evaluation of the daily nest survival for each of the 7 species resulted in Akaike weights spread nearly evenly over multiple competing models, indicating considerable model uncertainty (Table 4). Of the 17 models tested for each of the 7 species (119 total models), 22 were considered highly ranked (e.g., those with Akaike weights $>0.10$ and evidence ratios $<2.0)$. Of the 22 highly ranked models listed in Table 4, the effect of time since treatment (TIME) occurred in 9, followed by study site (SITE), which occurred in 8, TREAT, which occurred in 7 and TMTCAT which occurred in 5 models (Table 4). The model averaged effect estimates for all covariates in all models were considered weak, as $95 \%$ confidence intervals included 0 in all cases. Consequently, there was not much support for differences in daily nest survival based on the effects of treatment, treatment category, time since treatment, or even study site. Below, we report the estimated daily nest survival rates (DSR) and overall survival rates $(S)$ for each species based on the null or "constant survival model".

The American Robin had 3 competing models that included effects of study site, time since treatment, and an effect of treatment that was specific to study site (Table 4). Daily survival rates of robins were $0.96(95 \% \mathrm{CI}=0.95$, $0.97)$, while overall survival rates were $0.32(95 \% \mathrm{CI}=0.24$, $0.42)$.

The Dark-eyed Junco had 5 competing models with similar Akaike weights (Table 4). The top-ranked model suggested that nest survival of this species remained constant despite the implementation of the FFS treatments (Table 4). Other highly ranked models of consideration included effects of treatment category and time since treatment (Table 4). Daily nest survival of juncos was $0.96(95 \%$ CI $=0.96$, $0.97)$, while overall nest survival was $0.45(95 \% \mathrm{CI}=0.37$, $0.54)$.

The top-ranked model explaining the nest survival of the Dusky Flycatcher was constant survival. Two other models were considered highly ranked and included an effect of study site and a treatment effect not specific to treatment category (Table 4). Daily nest survival of flycatchers was 
Table 4. Model Selection Results Describing the Effects of Study Site, Treatment, Treatment Category, and Time Since Treatment on the Nest Survival of 8 Bird Species Observed at 8 Fire and Fire Surrogate Study Sites. Models Accounting for $\geq 0.10$ Akaike Weight are Ranked from the Most to Least Plausible Based on their $\triangle A I C c$ Score. Shown are the Number of Observed Nesting Intervals $\left(\mathbf{N}_{1}\right)$, the Number of Individual Nests $\left(\mathbf{N}_{2}\right)$, the Number of Parameters Contained in Each Model (K), AICc, $\triangle \mathrm{AIC} c$, Relative Model Weights, and Evidence Ratios

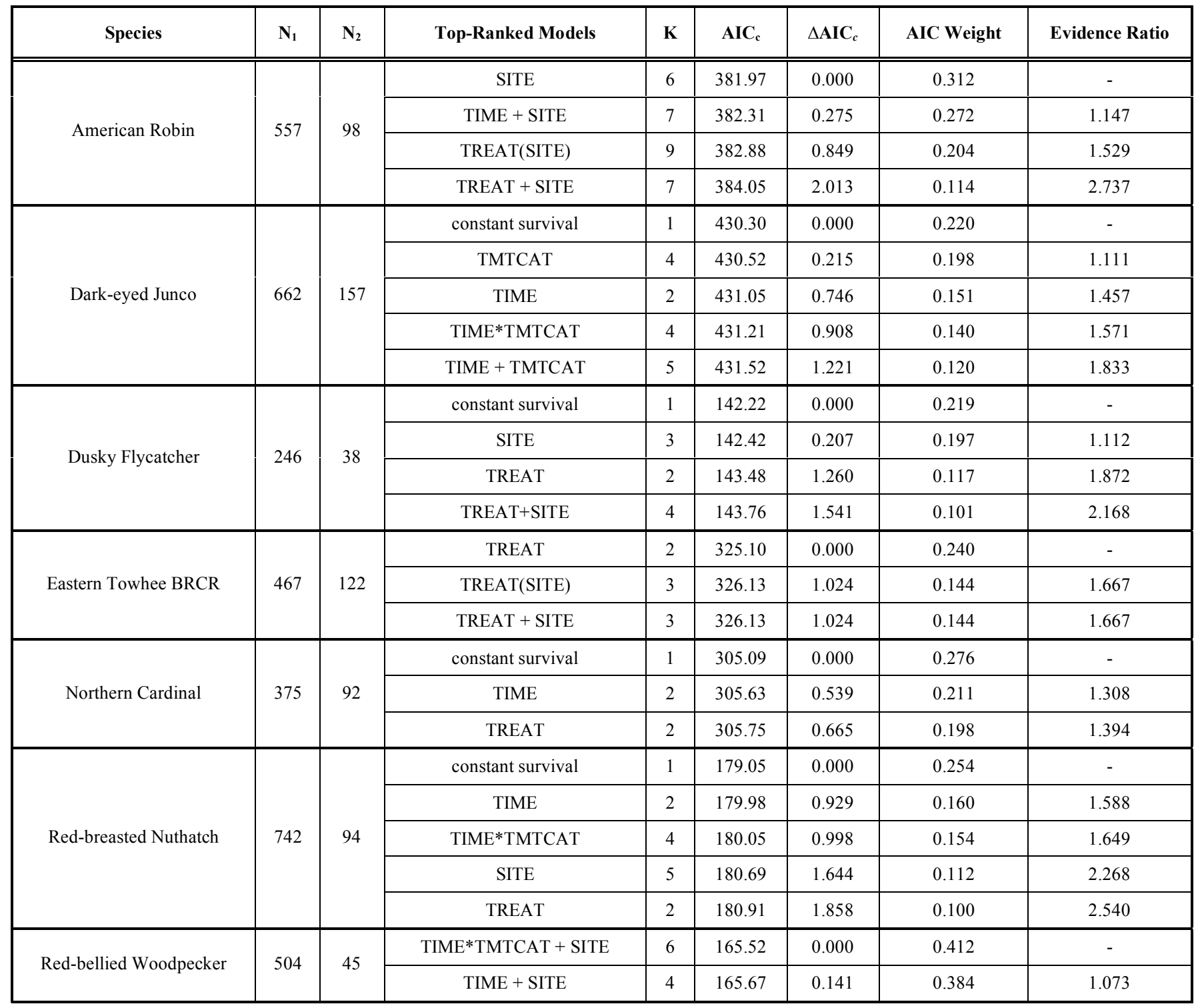

$0.97(95 \% \mathrm{CI}=0.96,0.98)$, while overall nest survival was $0.40(95 \% \mathrm{CI}=0.27,0.59)$.

Model selection results for the Red-breasted Nuthatch resulted in a top model of constant survival. Other topranking models included effects of time since treatment and treatment category. Daily nest survival for nuthatches was $0.992(95 \% \mathrm{CI}=0.988,0.996)$ and overall nest survival was $0.79(95 \% \mathrm{CI}=0.70,0.88)$.

The Eastern Towhee had a top-ranked model which included the single effect of treatment and two additional competing models which included nested and additive effects of study site, respectively (Table 4). The daily nest survival of towhees was $0.96(95 \% \mathrm{CI}=0.95,0.97)$ and the overall towhee survival rate was $0.43(95 \% \mathrm{CI}=0.34,0.54)$.
Nesting Northern Cardinals had a top-ranked model of constant survival, followed by 2 additional models of similar Akaike weight which included effects of time since treatment and a treatment effect not specific to treatment category (Table 4). The estimated daily nest survival of cardinals was $0.96(95 \% \mathrm{CI}=0.94,0.97)$ and overall nest survival was estimated to be $0.39(95 \% \mathrm{CI}=0.30,0.50)$.

Red-bellied Woodpeckers had a top-ranked model that included the interactive effects of time since treatment and treatment category as well as an additive effect of study site. A second, competing model included additive effects of time since treatment and study site (Table 4). The daily survival rate of woodpecker nests was $0.987(95 \%$ CI $=0.982$, $0.992)$, while the overall survival rate was $0.61(95 \% \mathrm{CI}=$ $0.50,0.75)$. 


\section{DISCUSSION AND CONCLUSIONS}

The primary goals of the FFS study were to examine the relative effects of different fuel-reduction treatments and to determine if effects were consistent across the study area network. We did not observe any strong treatment-dependent patterns in the nest survival responses to fuel reduction treatments in fire-dependent forests. In many instances, the treatments appeared to have minimal effect on survival, or the effect of study site overwhelmed any apparent treatment effect. The lack of a clear and/or consistent pattern in the responses of the species observed in this study could be due to several factors including relatively small sample sizes and the variability inherent within each of the study sites. An approach to meeting the challenges of high variability is to consider guilds of species that nest in similar locations, presuming that those guilds are more likely to experience similar factors that influence nest survival. We briefly discuss the results for each species within the context of the larger nesting guild they belong to.

\section{Ground Nesters}

Ground-nesting birds rely upon structural diversity in the forest understory to conceal their nests $[28,29]$. Consequently, any manipulation that reduces the structural diversity of the understory by removing shrubs, woody debris, or ground cover might be expected to result in a reduction in the nest survival of this nesting guild.

Across the FFS network, thinning treatments resulted in the largest increase in woody surface fuels [30], which could serve as effective cover for ground nesting birds. Thinning treatments that reduce the overstory canopy and leave behind slash may benefit ground-nesting birds by increasing both vegetative and structural diversity. Reducing tree and shrub density encourages the growth of grasses and forbs, while logging slash augments structural complexity, both of which enhance nest concealment. Lohr et al. [31] documented an increase in numbers of Eastern Towhee breeding territories in units that retained coarse woody debris. Thinning treatments in the mixed coniferous forests of the northern Sierra Nevada resulted in significantly greater numbers of ground-nesting birds, including the Dark-eyed Junco [32]. Similar increases in junco population density were noted in Douglas-fir forests of the Oregon Cascades [16]. Juncos also experienced increased nest survival following harvesting treatments that resulted in an increase in downed woody material in the central Appalachians of West Virginia [33].

The type of burning treatments implemented with the FFS study could result in short-term reductions in the suitability of habitat for ground nesting birds by reducing the availability of woody debris and leaf litter in the understory. Burning treatments tended to reduce overall surface fuels [30] and therefore nest cover for this group. However, the same fire may provide long-term benefits by encouraging greater production of grasses, forbs, and shrubs that provide cover for nests. Previous research on the two ground-nesting species within this data set indicates that fire is beneficial to their nest survival and these differences in results are likely due to temporal patterns of forest succession following the specific treatment, and are likely to depend on intensity of the treatment. Studies of Eastern Towhees suggest benefits from frequent controlled burning [28]. In Florida, towhee densities were highest about $4 \mathrm{yr}$ following fire in scrub and pinelands, followed by declines afterward in areas where fire was excluded and the understory became less complex [34]. In the old-growth mixed deciduous-coniferous forests of Minnesota, Dark-eyed Juncos, which were absent prior to fire, were considered important breeders 1 year following a wildfire that reduced tree numbers by $50 \%$ and greatly increased herb and forb cover [35].

\section{Shrub Nesters}

Our data did not substantially support a relationship between the FFS treatments and the nest survival of either the Dusky Flycatcher or Northern Cardinal, which remained constant regardless of treatment. The nesting requirements of this guild include a diverse layer of shrubs in which to conceal their nests, so treatments that result in a decline of this vegetative layer could have a negative impact on these species. Implementation of the FFS treatments resulted in initial declines in shrub cover across the entire network, especially in burned areas [30]. These declines were reversed in subsequent years as the understory and shrub layers regained vigor [30]. Given these habitat changes, one might expect to see an initial decrease in the nest survival of these bird species, followed by an increase as the shrub layer recovers. Very little data exists on the effects of fire and forest thinning on the nest survival of either of these species. Abundance data from forests in the west suggest that the Dusky Flycatcher may be adversely affected by fire, but many studies lack strong evidence and/or are conducted in post-wildfire environments where severity is highly variable $[15,36,37]$. There is some evidence to suggest that Dusky Flycatchers may have a positive response to older post-fire environments [36] where the shrub community has matured and provides adequate nesting habitat. A similar, delayed positive response was noted by Siegel and DeSante [32] in the mixed conifer forests of the northern Sierra Nevada, CA. In a comparison of thinned and un-thinned forests, they found increases in both density and nest survival of the Dusky Flycatcher 5-8 years following treatments; increases likely due to the improved vigor in the shrub layer resulting from thinning. Northern Cardinals may also exhibit increased nest survival as vegetation recovers after disturbance if concealment improves nest survival. Available data suggests that the species experiences moderate to low nest survival in many locations studied to date, but is very tolerant of habitat disturbance [38]. In the Gulf Coastal Plain study site, which had the largest sample sizes of nests, cardinal nest survival was variable and not clearly associated with treatments [39].

\section{Tree Nesters}

The American Robin was the only representative from this nesting guild and its daily nest survival was most influenced by variation in study site. In the coniferous forests of western North America, this species relies on medium to large live trees for nesting and has been associated with both early and late seral forests [40]. Previous research investigating the effects of fire and thinning treatments on this species have focused primarily on abundance or occupancy measures and have noted positive effects following fire in the Southwest [41] and mixed responses in both the maritime Pacific Northwest [42] and Rocky 
Mountains [37]. In the eastern Cascades of northern California, George and Zack [43] noted higher occupancy rates in thinned and thin-burn treated areas. We could only find one study that examined the effects of fuel-reduction treatments on nest survival; Siegal and DeSante [32] noted greater abundances in thinned areas as compared to controls, but less successful nests in the mixed-conifer forests of the northern Sierra Nevada.

\section{Snag Nesters}

Cavity-nesting species such as the Red-breasted Nuthatch and the Red-bellied Woodpecker rely primarily on large snags for their foraging and nesting habits. Large live trees are also an important component of long-term habitat quality as they are eventually recruited into the snag population. Fuel reduction treatments that reduce the density of large snags may initially be detrimental to the overall nest density and nest survival of these species. However, treatments resulting in an increase in the mean diameter of live trees could enhance long-term habitat quality through the eventual recruitment of larger snags. Across the FFS network, mechanical thinning alone and thinning followed by prescribed fire resulted in the largest increases in the mean diameter of live trees, but also the greatest removal of snags [30] and could explain the lower nest survival estimates we observed for the Red-bellied Woodpecker in these treatment areas.

While fuel reduction treatments, especially burning, often result in an increase in snag density, this increase is typically dominated by snags in the smaller diameter classes [44] that are not of primary use to snag-nesting birds [45]. These same burns can also consume existing snags [44], leading to reductions in habitat quality for snag-dependent species. However, long-term implementation of prescribed burn programs that resemble historic regimes can result in subsequent fires of lower intensity and preservation of existing large snags [46]. The opposing effects of fuelreduction treatments on the density of snags may lead to a mixed response by nuthatches and woodpeckers depending on the study site and treatment intensity and might partially explain why the nest survival of Red-breasted Nuthatches remained constant despite treatments and across multiple study sites.

Red-bellied Woodpecker nests showed a trend toward decreased survival as time since treatment advanced. Treatments experiencing a burn, or thinning and a burn, tended to exhibit the time effect in two of the three study sites where Red-bellied Woodpeckers nested. Why this time trend would appear in those treatments but not in treatments that were only thinned remains unclear. Future investigations could evaluate the possibility that burning indirectly reduced food supply of woodpeckers.

Little information exists documenting the nest survival of snag-nesting species in relation to forest thinning treatments, except post-fire salvage, where results are mixed [47, 48]. Post-fire salvage logging is not comparable to the thinning operations conducted as part of this study, however, as its focus is on the removal of fire-damaged timber and often results in a significant decline in large trees or snags remaining after a wildfire event, whereas the thinning implemented during fuel-reduction treatments typically removes small-diameter trees and is designed to reduce vertical ladder fuels and to increase spacing between crowns of the remaining over-story trees [7].

\section{CONCLUSIONS}

The FFS Project was intended to provide detailed information on the response of several ecological variables to the implementation of fuel reduction treatments in forest systems historically dominated by frequent, low-intensity fires. From a wildlife perspective, this information is critical to understanding how increasingly common forest management treatments may affect habitat features critical to wildlife of interest within a particular region.

The variable nature of our results renders us unable to make any reliable broad predictions about the short-term effects of fuel-reduction treatments on avian nest survival and leads us to suggest that managers whose goals include maintenance of bird communities in conjunction with fuelreduction treatments should adopt an adaptive management approach designed for their specific forest type or species of interest.

It is important to note that the study design implemented with the FFS, which was originally intended to primarily quantify changes in vegetation and fuels resources, presented two distinct challenges in the attempt to effectively estimate treatment effects on avian nest survival. First, the 10 ha plot size was prohibitively small and precluded our ability to locate and monitor an adequate number of nests. The small sample sizes presented here are likely one of the primary reasons for our inability to detect any strong treatment responses. Second, the temporal scope of this study only enabled the quantification of short-term changes in avian nest survival in response to fuel reduction treatments. When considering the historic fire-return intervals represented by the sites across the research network, our results should be considered with caution. Habitat changes within the first few years following fire, especially in stands where fire has been excluded for many years, can be dramatic and the responses of birds, either positive or negative, may not represent responses that occurred when natural fires were recurring at typical return intervals. Time since fire has been identified as an important predictor of avian community patterns $[15,49,50]$ and should be a primary consideration when attempting to interpret avian nest survival in response to any sort of fuel reduction treatment. An understanding of the long-term consequences associated with fire-restoration treatments is needed for managers to critically evaluate the trade-offs between possible short-term reductions in avian nest survival with potential long-term gains in habitat quality resulting from restoration activities.

\section{ACKNOWLEDGEMENTS}

This is Contribution Number 155 of the National Fire and Fire Surrogate Project (FFS). This research was funded by the U.S. Joint Fire Science Program and supported by the Wildlife Conservation Society. We thank K. Outcalt for editorial assistance with previous versions of this manuscript, as well as suggestions from three anonymous reviewers. This research would not have been successful without the hard work of the numerous field assistants that 
collected detailed nesting data across the national network of FFS sites.

\section{REFERENCES}

[1] Agee JK. Fire ecology of Pacific Northwest forests. Washington DC: Island Press 1993.

[2] Allen CD, Savage M, Falk DA, et al. Ecological restoration of southwestern ponderosa pine ecosystems: a broad perspective. Ecol Appl 2002; 12: 1418-33.

[3] Covington WW, Moore MM. Southwestern ponderosa forest structure: changes since Euro-American settlement. J For 1994; 92: 39-47.

[4] Covington WW, Fule PZ, Moore MM, et al. Restoring ecosystem health in ponderosa pine forests of the Southwest. J For 1997; 95: 23-9.

[5] Fulé P., Waltz AEM, Covington WW, Heinlein TA. Measuring forest restoration effectiveness in reducing hazardous fuels. J For 2001; 99: 24-9.

[6] Brown RT, Agee JK, Franklin JF. Forest restoration and fire: principles in the context of place. Conserv Biol 2004; 18: 903-12.

[7] Agee JK, Skinner CN. Basic principles of forest fuel reduction treatments. For Ecol Manage 2005; 211: 83-96.

[8] Fulé PZ, McHugh C, Heinlein TA, Covington WW. Potential fire behavior is reduced following forest restoration treatments. In: Vance RK, Edminster CB, Covington WW, Blake JA, Eds. Ponderosa pine ecosystems restoration and conservation: steps toward stewardship. USDA Forest Service Proceedings RMRS-P22. 2001; pp 28-35.

[9] Omi PN, Martinson EJ. Effectiveness of thinning and prescribed fire in reducing wildfire severity. In: Murphy DD, Stine PA, Eds. Proceedings of the Sierra Nevada Science Symposium, USDA For. Ser. Gen. Tech. Rep. PSW-GTR-193. 2004; pp 87-92.

[10] Noss RF, Franklin JF, Baker WL, Schoennagel T, Moyle PB. Managing fire-prone forests in the western United States. Front Ecol Environ 2006; 4: 481-7.

[11] Pilliod DS, Bull EL, Hayes JL, Wales BC. Wildlife and invertebrate response to fuel reduction treatments in dry coniferous forests of the Western United States: a synthesis. USDA Forest Service General Technical Report RMRS-GTR-173, 2006.

[12] McIver JD, Boerner REJ, Hart SC. The national fire and fire surrogate study: Ecological consequences of alternative fuel reduction methods in seasonally dry forests. For Ecol Manage 2008; 255 : 3075-80

[13] Hutto RL. Composition of bird communities following standreplacement fires in Northern Rocky Mountain (U.S.A.) conifer forests. Conserv Biol 1995; 9: 1041-58.

[14] Kotliar NB, Kennedy PL, Ferree K. Avifaunal responses to fire in southwestern montane forests along a burn severity gradient. Ecol Appl 2007; 17: 491-507.

[15] Smucker KM, Hutto RL, Steele BM. Changes in bird abundance after wildfire: importance of fire severity and time since fire. Ecol Appl 2005; 15: 1535-49.

[16] Hagar J, Howlin S, Cario L. Short-term response of songbirds to experimental thinning of young Douglas-fir stands in the Oregon Cascades. For Ecol Manage 2004; 199: 333-47.

[17] Robertson BA, Hutto RL. Is selectively harvested forest an ecological trap for Olive-sided Flycatchers? Condor 2007; 109: 109-21.

[18] Van Horne B. Density as a misleading indicator of habitat quality. J Wildl Manage 1983; 47: 893-901.

[19] Vickery PD, Hunter Jr ML, Wells JV. Is density an indicator of breeding success? Auk 1992; 109: 706-10.

[20] Martin TE, Paine CR, Conway C J, Hochachka WM, Allen P, Jenkins W. BBIRD Field Protocol. Montana Cooperative Wildlife Research Unit, University of Montana, Missoula, Montana, USA 1997.

[21] Shaffer TL. A unified approach to analyzing nest success. Auk 2004; 121: 526-40.

[22] Rotella JJ, Dinsmore SJ, Shaffer TL. Modeling nest-survival data: a comparison of recently developed methods that can be implemented in MARK and SAS. Anim Biodivers Conserv 2004; 27: 187-05.

[23] Mayfield H. Nesting success calculated from exposure. Wilson Bull 1961; 87: 456-66.
[24] SAS Institue. SAS/STAT software. Version 9.0. SAS Institute, Cary, North Carolina, USA. 2003.

[25] Akaike H. Information theory as an extension of the maximum likelihood principle. In: Petrov BN, Csaki F, Eds. Second International Symposium on Information Theory; Budapest, Hungary: Akademiai Kiado 1973; pp267-81.

[26] Hurvich CM, Tsai CL. Regression and time series model selection in small samples. Biometrika 1989; 76: 297-307.

[27] Burnham KP, Anderson DR. Model selection and multi-model inference: a practical information-theoretic approach. $2^{\text {nd }}$ ed. New York: Springer-Verlag 2002.

[28] Greenlaw JS. Eastern Towhee (Pipilo erythrophthalmus). In The Birds of North America, No. 262 (A. Poole and F. Gill, eds.). Philadelphia: The Academy of Natural Sciences, and PA, and Washington, DC: The American Ornithologists' Union 1996.

[29] Nolan Jr V, Ketterson ED, Cristol DA, et al. Dark-eyed Junco (Junco hyemalis). In The Birds of North America, No. 716 (In: Poole A, Gill F, eds.). The Birds of North America, Inc., Philadelphia, PA. 2002.

[30] Schwilk DW, Keeley JE, Knapp EE, et al. The national Fire and Fire Surrogate study: effects of fuel reduction methods on forest vegetation structure and fuels. Ecol Appl 2009; 19: 285-304.

[31] Lohr SM, Gauthreaux SA, Kilgo JC. Importance of coarse woody debris to avian communities in loblolly pine forests. Conserv Biol 2002; 16: 767-77.

[32] Siegel RB, DeSante DF. Bird communities in thinned versus unthinned Sierran mixed conifer stands. Wilson Bull 2003; 115: $155-65$.

[33] Weakland CA, Wood PB, Ford WM. Responses of songbird to diameter-limit cutting in the central Appalachians of West Virginia, USA. For Ecol Manage 2002; 155: 115-29.

[34] Engstrom RT, Crawford RL, Baker WW. Breeding bird populations in relation to changing forest structure following fire exclusion: a 15-year study. Wilson Bull 1984; 96: 437-50.

[35] Apfelbaum S, Haney A. Bird populations before and after wildfire in a Great Lakes pine forest. Condor 1981; 83: 347-54.

[36] Kennedy PL, Fontaine JB. Synthesis of knowledge on the effects of fire and fire surrogates on wildlife in U.S. dry forests. Special Report 1096. Extension and Experiment Station Communications. Oregon State University 2009; pp 1-132.

[37] Saab VA, Powell HDW. Fire and avian ecology in North America: process influencing pattern. Stud Avian Biol 2005; 30: 1-13.

[38] Halkin SL, Linville SU. Northern Cardinal (Cardinalis cardinalis), The Birds of North America Online (A. Poole, Ed.). Ithaca: Cornell Lab of Ornithology; Retrieved from the Birds of North America Online: http://bna.birds.cornell.edu/bna/species/440 doi:10.2173/ bna.440; 1999 .

[39] Robinson WD, Rompré G. Nest survival of understory birds in longleaf pine forests exposed to fire and fire-surrogate treatments. Open Environ Sci J 2010; 4: 71-7.

[40] Sallabanks R, James FC. American Robin (Turdus migratorious), The birds of North America Online (A. Poole, Ed.). Ithaca: Cornell Lab of Ornithology; Retrieved from the Birds of North America Online: http://bna.birds.cornell.edu/bna/species/462 1999.

[41] Bock CE, Block WM. Fire and birds in the southwestern United States. Stud Avian Biol 2005; 30: 14-32.

[42] Huff MH, Seavy NE, Alexander JD, Ralph CJ. Fire and birds in the Maritime Pacific Northwest. Stud Avian Biol 2005; 30: 46-62.

[43] George TL, Zack S. Bird occupancy and richness in ponderosa pine forests with contrasting forest structure and fire history. Can J For Res 2008; 38: 936-42.

[44] Stephens SL, Moghaddas JJ. Fuel treatment effects on snags and coarse woody debris in a Sierra Nevada mixed conifer forest. For Ecol Manage 2005; 214: 53-64.

[45] Laudenslayer WF. Nesting bird use of snags in eastside pine forests. In: Laudenslayer, Jr, WF, Shea PJ, Valentine BE, Weatherspoon PC, Lisle TE, Technical Coordinators. Proceedings of the Symposium on the Ecology and Management of Dead Wood in Western Forests. USDA Forest Service General Technical Report PSW-GTR-181, 1999.

[46] Stephens SL. Fuel loads, snag density, and snag recruitment in an unmanaged Jeffrey pine-mixed conifer forest in northwestern Mexico. For Ecol Manage 2004; 199: 103-13.

[47] Saab VA, Dudley JG. Responses of cavity nesting birds to standreplacement fire and salvage logging in ponderosa pine/Douglas-fir 
forests of southwestern Idaho. USDA Forest Service Research Paper RMRS-RP-11, 1998.

[48] Saab VA, Russell RE, Dudley JG. Nest densities of cavity-nesting birds in relation to postfire salvage logging and time since wildfire. Condor 2007; 109: 97-108.
[49] Covert-Bratland KA, Block WM, Theimer TC. Hairy woodpecker winter ecology in ponderosa pine forests representing different ages since wildfire. J Wildl Manage 2006; 70: 1379-92.

[50] Hutto RL, Gallo S M. The effects of postfire salvage logging on cavity-nesting birds. Condor 2006; 108: 817-31.

(C) Farris et al.; Licensee Bentham Open.

This is an open access article licensed under the terms of the Creative Commons Attribution Non-Commercial License (http://creativecommons.org/licenses/by$\mathrm{nc} / 3.0 /$ ) which permits unrestricted, non-commercial use, distribution and reproduction in any medium, provided the work is properly cited. 